[Agr. Biol. Chem., Vol. 27, No. 12, p. 858 863, 1963]

\title{
Biochemical Effects of Fatty Acid and its Derivatives on L-Glutamic Acid Fermentation
}

\author{
Part I. Accumnlation of L-Glutamic Acid in the Presence of \\ Sucrose Fatty Acid Ester ${ }^{\dagger}$
}

\author{
By Kôichi Takinami, Hiroshi Okada and Toshinao Tsunoda \\ Central Research Laboratory of Ajinomoto Co., Inc., Kawasaki \\ Received August 15, 1963
}

\begin{abstract}
It has been found that although Brevibacterium lactofermentum No. 2256 is incapable of accumulating L-glutamic acid in a biotin sufficient medium, it produces a large quantity of the acid in the presence of sucrose fatty acid ester. In a biotin deficient medium, however, the ester brought the unfavorable diminution of L-glutamic acid accumulation caused by the decrease of glucose consumption in an incubation period. The undesirable effects were practically lost when the ester was added to the culture medium after more than eight hours in the course of incubation. This fact suggests that the ester is concerned with the growth of microorganism. It is very interesting to elucidate the interrelation between sucrose fatty acid ester and biotin. For the maximum accumulation of L-glutamic acid corresponding increase in amount of the ester to the increasing concentration of biotin was necessary. The proportional relation did not extend to excedingly high levels of the two implicating factors. The further observations concerning the effects of the individual fatty acid esters such as sucrose stearate remain unsatisfactory.
\end{abstract}

\section{INTRODUCTION}

It is well known that a deficient amount of biotin exerts L-glutamic acid producing bacteria to accumulate in a culture medium a large quantity of the acid $^{1 \sim 6)}$. Few papers ${ }^{7)}$ described the possibility of the formation of L-glutamic acid at high levels of biotin which are rather natural for bacteria.

On the other hand, unsaturated fatty acid

$\dagger$ This report was partially presented at the meeting of the Association of Amino Acid Fermentation, Tokyo, May 22nd, 1963.

1) K. Tanaka, T. Iwasaki and S. Kinoshita, J. Agr. Chem. Soc. Japan, 34, 593 (1960).

2) K.C. Chao and J.W. Foster, J. Bacteriol., 77, 715 (1959).

3) K. Oishi, K. Aida and T. Asai, J. Agr. Chem. Soc. Japan, 35, 855 (1961).

4) S. Okumura, R. Tsugawa and T. Tsunoda, ibid., 36, 197 (1962).

5) I. Shiio, S. Otsuka and M. Takahashi, J. Biochem., 51, 67 (1962).

6) K. Miyai, R. Kodaira, I. Tsuruo, K. Goto and T. Akimoto, This Journal, 27, 243 (1963).

7) K. Udagawa, S. Abe and S. Kinoshita, J. Fermentation Technology, 40, 614 (1962). requirements have been demonstrated for several microorganisms. For instance, oleic acid was the first observed to be essential for $C$. diphtheriae $^{8)}$ and several lactic acid bacteria $^{9,10)}$. Recently it has been also found that glutamic acid producing bacteria are stimulated to grow ${ }^{1)}$ and produce L-glutamic acid from glucose ${ }^{11}$ ) with oleic acid as well as with biotin. The relation of saturated fatty acid to the biotin requirement of $\mathrm{L}^{-}$ glutamic acid producing bacteria has never bcen discussed. However, it is significant

\footnotetext{
8) S. Cohen, J.C. Snyder and J.H. Mueller, J. Bacteriol., 41, 581 (1941).

9) W.L. Williams, H.P. Broquist and E.E. Snell, J. Biol. Chem., 170, 619 (1947).

10) V.R. Williams and E.A. Fieger, ibid., 166, 335 (1946).

11) S. Okumura, R. Tsugawa, T. Tsunoda and S. Motozaki, J. Agr. Chem. Soc. Japan, 36, 204 (1962).
} 
that most of the saturated acids have been observed not to possess growth stimulating activity. Long chain saturated fatty acid would be expected to exert an effect different from that of unsaturated acid.

To facilitate the experimentation, sucrose fatty acid ester which is soluble in water was used in this investigation. The sucrose ester, usually called sugar ester, was practically prepared from sucrose and the methyl ester of fatty acid $^{12)}$, and has been known as one of fatty acid derivatives without any biological toxicity ${ }^{13)}$. It will be interesting to investigate the biochemical action of the sugar ester to which little attention has been paid.

\section{EXPERIMENTAL}

Microorganism. Brevibacterium lactofermentum No. 2256 14 was used for the experiment.

Inoculum. Inoculum of Brev. lactofermentum No. 2256 was prepared using reciprocal shaker at $31.5^{\circ} \mathrm{C}$ in a $500 \mathrm{ml}$ flask containing $100 \mathrm{ml}$ of medium, the composition of which was as follows: glucose, $50 \mathrm{mg} /$ $\mathrm{ml}$; urea, $6 \mathrm{mg} / \mathrm{ml}$; $\mathrm{KH}_{2} \mathrm{PO}_{4}, 1 \mathrm{mg} / \mathrm{ml}$; $\mathrm{MgSO}_{4} \cdot 7 \mathrm{H}_{2} \mathrm{O}$, $0.4 \mathrm{mg} / \mathrm{ml} ; \mathrm{FeSO}_{4} \cdot 7 \mathrm{H}_{2} \mathrm{O}, 10 \mu \mathrm{g} / \mathrm{ml} ; \mathrm{MnSO}_{4} \cdot 4 \mathrm{H}_{2} \mathrm{O}, 8.1$ $\mu \mathrm{g} / \mathrm{ml}$; biotin, $2 \mu \mathrm{g} / \mathrm{ml}$; dry yeast, $2 \mathrm{mg} / \mathrm{ml}$.

Fermentation. One liter of basal medium contained $100 \mathrm{~g}$ of glucose, $60 \mathrm{~g}$ of urea, $1 \mathrm{~g}$ of $\mathrm{KH}_{2} \cdot \mathrm{PO}_{4}$, $0.4 \mathrm{~g}$ of $\mathrm{MgSO}_{4} \cdot 7 \mathrm{H}_{2} \mathrm{O}, 8.1 \mathrm{mg}$ of $\mathrm{MnSO}_{4} \cdot 4 \mathrm{H}_{2} \mathrm{O}$ and $10 \mathrm{ml}$ of Ajinomoto's Aji-eki (hydrolysate of soybean protein). Sucrose fatty acid ester and biotin were usually added to the basal medium (except Fig. 2). Twenty $\mathrm{ml}$ of the medium was put into a $500 \mathrm{ml}$ shake flask and then sterilized. To the medium was added one $\mathrm{ml}$ of the previously prepared inoculum. Fermentation was carried out at $31.5^{\circ} \mathrm{C}$ for forty-two hours on a reciprocal shaker. In order to keep the culture medium slightly alkaline, $45 \%$ aqueous solution of urea was added to the medium during the course of incubation.

Analysis. Glucose in the culture medium was determined according to the method of Fehling Lehmann Schoorl. L-Glutamic acid was determined by

12) L. Osipow, F.D. Snell, W.C. York and A. Finchler, Ind. Eng. Chem., 48, 1459 (1956).

13) L. Osipow et al., ibid., 48, 1462 (1956).

14) S. Okumura, R. Tsugawa, T. Tsunoda, K. Kono, T. Matsui and N. Miyaji, J. Ag'. Chem. Soc. Japan, 36, 141 (1962). the manometric method using L-glutamic acid decarboxylase preparation obtained from dried cells of Escherichia coli Crookes. Bacterial growth was estimated by measuring the turbidity of the cell suspension, which was prepared by diluting the culture medium 26-fold with deionized water. Gas chromatography was applied to the analysis of the fatty acid of sucrose ester. The sucrose fatty acid ester was saponified with alcoholic potash and the isolated fatty acid was then derived to methyl ester in the methanol solution of sulfuric acid. The individual fatty acid methyl ester was separated on the chromatogram with diethylene glycol succinate polyester column.

\section{MATERIALS}

Sucrose Fatty Acid Ester. Commercial Nitto Ester, the water content of which was determined to be $57.9 \%$, was dried over phosphorus pentoxide in vacuo and then used in the fermentation. This anhydrous ester is a mixture of mono-, di- and tri-ester of various fatty acids. The composition of the fatty acids analysed by gas chromatography is shown in Table $I$.

\section{TABle I. FATTY ACID COMPOSITION OF THE} SUCROSE FATTY ACID ESTER

$\begin{array}{lr}\text { Fatty acid } & \% \\ \text { Capric } & 0.6 \\ \text { Lauric } & 1.1 \\ \text { Myristic } & 8.0 \\ \text { Palmitic } & 39.9 \\ \text { Stearic } & 45.8\end{array}$

Authentic Samples of Sucrose Ester.* The purity of the authentic sample of sucrose monolaurate is $90.4 \%$; sucrose monopalmitate, $94.4 \%$; sucrose monostearate, $92.1 \%$.

\section{RESULTS AND DISCUSSION}

Effect of Sucrose Fatty Acid Ester on the Consumption of Glucose and the Accumulation of L-Glutamic Acid.

A deficient amount of biotin, $5 \mu \mathrm{g}$ per liter, was required for the most efficient accumulation of L-glutamic acid in this investigation. Twenty $\mu \mathrm{g}$ or more of biotin per liter prevented the formation of the acid. But the addition of sucrose fatty acid ester brought a noteworthy effect; the ester depressed the

* These samples were kindly supplied by the Central Reserch Laboratory, Dai-Nippon Sugar Manufacturing Co., Ltd. 

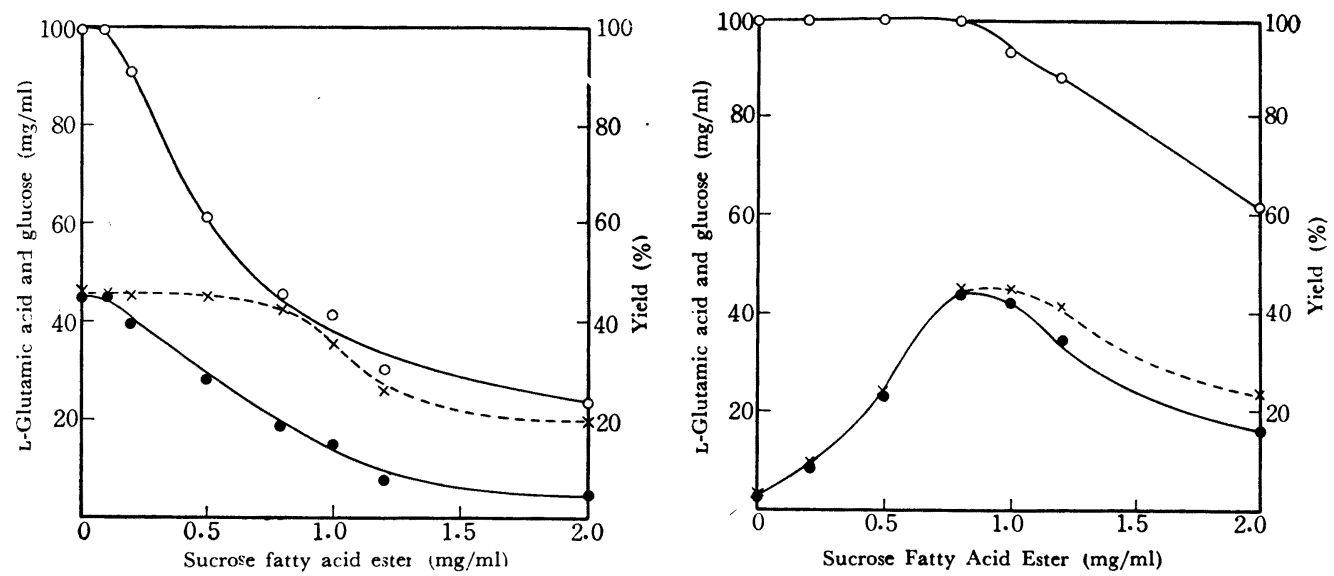

FIG. 1. Effect of Sucrose Fatty Acid Ester on Glucose Consumption and L-Glutamic Acid Accumulation.

$$
\begin{aligned}
& \text { Left : Biotin } 5 \mu \mathrm{g} / 1 . \\
& \text { Consumed glucose. }
\end{aligned}
$$

formation of L-glutamic caid when there being deficient amount of biotin, but conversely in the medium containing sufficient amount of biotin it remarkably increased the accumulation of the acid. As shown in Fig. 1, when biotin was deficient ( $5 \mu \mathrm{g}$ per liter), the proportion of the accumulated L-glutamic acid to the consumed glucose did not change with the amount of the ester unless it was over $0.8 \mathrm{mg}$ per $\mathrm{ml}$. The depression of glucose consumption in the incubation period caused the decrease in the accumulation of L-glutamic acid; if the incubation period is greatly prolonged, no decrease may occur eventually. When the concentration was over $0.8 \mathrm{mg}$ per $\mathrm{ml}$, the ester not only regulated the glucose consumption but brought about growth inhibition, resulting in the diminution of the yield of the acid. The same effects were observed when biotin was $20 \mu \mathrm{g}$ per liter and the ester was over $0.8 \mathrm{mg}$ per $\mathrm{ml}$. It is shown in the right of Fig. 1 that in order to get the maximum formation of L-glutamic acid $0.8 \mathrm{mg}$ of the ester per $\mathrm{ml}$ was required, where no depression of glucose consumption occurred. As long as the concentration was less than $0.8 \mathrm{mg}$ per $\mathrm{ml}$, the ester promoted the formation of L-glutamic acid in proportion to its amount. Details of experiments on the growth inhibition of fatty acids are to be reported in the succeeding papers.

Influence of Addition of Sucrose Fatty Acid Ester in the Course of Incubation.

In the very significant concentration described above $(0.8$ and $1.2 \mathrm{mg} / \mathrm{ml})$, sucrose fatty acid ester added within eight hours in the course of incubation, as shown in Fig. 2, increased L-glutamic acid formation in the medium containing sufficient biotin, and on the contrary decreased it in a biotin deficient medium. These influences were exactly like those of the ester added to the medium before inoculation. When added after over eight hours, the ester had no effect. This critical time was just in accord with the middle of logarithmic phase of growing bacteria, as indicated in Fig. 3. Therefore sucrose fatty acid ester seems to have influences upon bacterial growth as well as upon the accumulation of L-glutamic acid.

Interrelation of Sucrose Fatty Acid Ester to Biotin.

The effect of adding sucrose fatty acid ester 

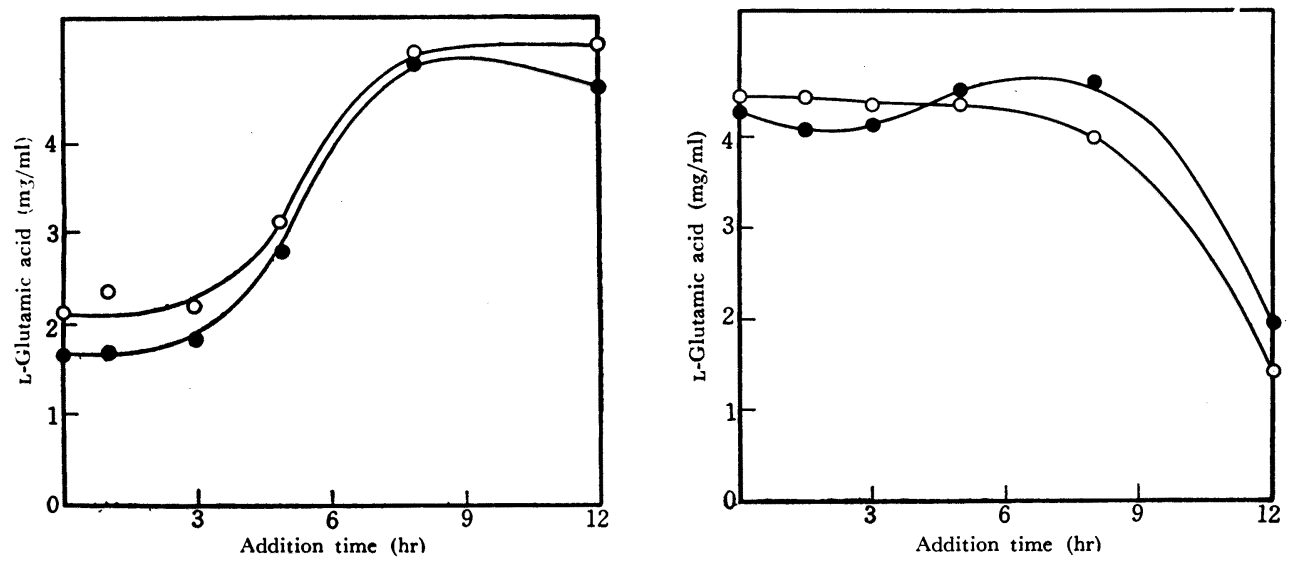

FIG. 2. Influence of Addition of Sucrose Fatty Acid Ester During Incubation. Left : Biotin $; \mu \mathrm{g} / 1$. Right: Biotin $20 \mu \mathrm{g} / 1$.

- - : L-Glutamic acid accumulated by adding sucrose fatty acid $0.8 \mathrm{mg} / \mathrm{ml}$. : L-Glutamic acid accumulated by adding sucrose fatty acid $1.2 \mathrm{mg} / \mathrm{ml}$.

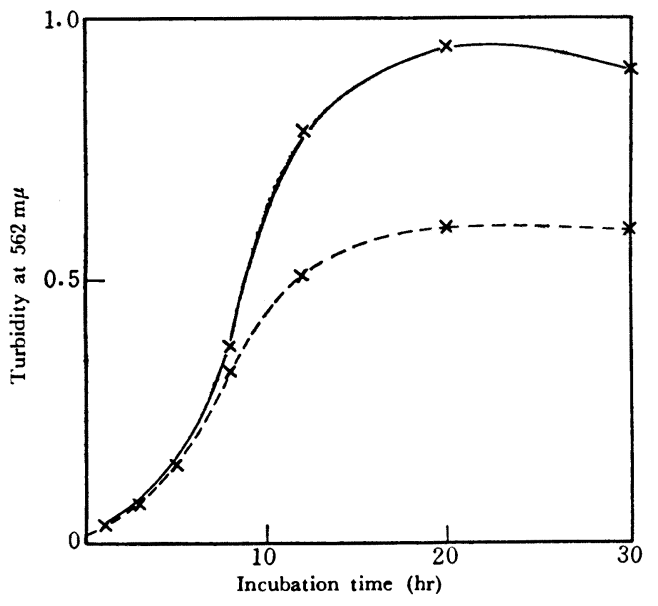

FIG 3. Growth Curve of Brev. lactofermentum No. 2256.

- $\times$ - : Growth in the medium containing biotin $20 \mu \mathrm{g} / 1$ $\ldots-\ldots-\ldots$ : Growth in the medium containing biotin $5 \mu \mathrm{g} / 1$.

and biotin to the basal medium in various concentrations is shown in Table II, and some interrelation between these two factors is given in Fig. 4. It was to a certain degree that the ester added increasingly in proportion to the concentration of biotin played an important part in accumulating L-glutamic acid. The effect was not observed at higher
TABLE II. ACCUMUlation OF L-GLUTAMIC ACID IN THE PRESENCE OF VARIOUS CONCENTRATIONS OF Sucrose FatTy AcId ESTER (SFAE) AND BIOTIN

\begin{tabular}{crrrrr}
$\begin{array}{c}\text { BFAE } \\
(\mathrm{mg} / \mathrm{ml})\end{array}$ & \multicolumn{1}{c}{$\begin{array}{c}\text { Biotin }(\mu \mathrm{g} / \mathrm{l}) \\
0\end{array}$} & \multicolumn{1}{c}{10} & \multicolumn{1}{c}{15} & \multicolumn{1}{l}{20} & \multicolumn{1}{c}{30} \\
0 & 44.1 & 23.0 & 6.0 & 2.6 & 1.7 \\
0.2 & 39.5 & 42.7 & 32.0 & 8.5 & 4.7 \\
0.5 & 28.3 & 40.4 & 42.7 & 23.2 & 29.7 \\
0.8 & 19.1 & 35.0 & 42.8 & 44.4 & 38.8 \\
1.0 & 14.8 & 28.2 & 35.0 & 41.9 & 41.0 \\
1.2 & 7.9 & 23.3 & 33.7 & 33.6 & 39.2 \\
2.0 & 3.8 & 7.8 & 15.2 & 16.3 & 16.7
\end{tabular}

The values are L-glutamic acid accumulated $(\mathrm{mg} / \mathrm{ml})$.

levels of the two factors. For instance, Lglutamic acid was not obtained at all in the presence of $100 \mu \mathrm{g}$ of biotin in one liter of medium in spite of an adequate amount of the ester. Since the ester is not completely soluble in water and easily associates itself to form giant molecule in higher concentration above $2 \mathrm{mg}$ per $\mathrm{ml}$, it seems unable to demonstrate thoroughly the effect. The combinations of sucrose fatty acid ester and biotin necessaly to obtain L-glutamic acid formation over $40 \mathrm{mg}$ per $\mathrm{ml}$ are plotted in Fig. 4 . The optimum amounts of the two factors for the 


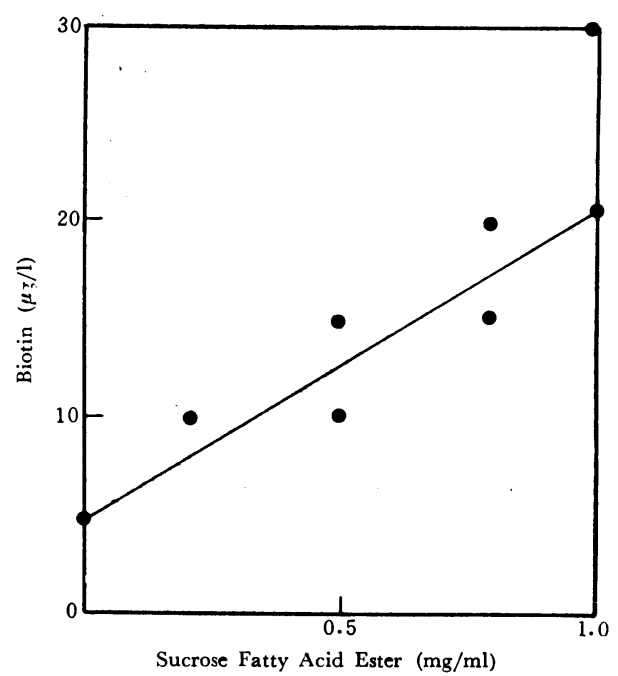

FIG. 4. Interrelation of Sucrose Fatty Acid Ester to Biotin.

The amounts of sucrose fatty acid ester and biotin, when L-glutamic acid over $40 \mathrm{mg} / \mathrm{ml}$ was accumulated, are plotted.

maximum production of L-glutamic acid might be induced to be on the plotted curve.

Effects of the Sucrose Esters of Several Fatty Acids on the Formation of L-Glutamic Acid.

The sucrose fatty acid ester used in the preceding experiments is considered a mixture of sucrose caprate, laurate, myristate, palmitate and stearate, as indicated in Table I. In order to clarify the difference of the

TABLE III. EFFEcts OF SUCROSE MONOLAURATE, AND MONOSTEarate ON THE PRODUCTION OF LGLUTAMIC ACID.

\begin{tabular}{|c|c|c|}
\hline & $\begin{array}{c}\text { Ester } \\
(\mathrm{mg} / \mathrm{ml})\end{array}$ & $\begin{array}{l}\text { L-Glutamic Acid } \\
(\mathrm{mg} / \mathrm{ml})\end{array}$ \\
\hline Laurate & $\left\{\begin{array}{l}0.1 \\
0.4 \\
1.0\end{array}\right.$ & $\begin{array}{l}2.9 \\
4.9 \\
0\end{array}$ \\
\hline Palmitate & $\left\{\begin{array}{l}0.1 \\
0.4 \\
1.0\end{array}\right.$ & $\begin{array}{l}4.5 \\
0 \\
0\end{array}$ \\
\hline Stearate & $\left\{\begin{array}{l}0.1 \\
1.0 \\
1.2 \\
1.4 \\
2.0\end{array}\right.$ & $\begin{array}{r}2.0 \\
20.9 \\
28.4 \\
36.0 \\
17.1\end{array}$ \\
\hline None & 0 & 1.7 \\
\hline
\end{tabular}

Esters were added to the culture medium containing $20 \mu \mathrm{g}$ of biotin per liter before inoculation. effects of the individual esters in the mixture, sucrose monolaurate, monopalmitate and monostearate were taken up and examined severally in a manner similar to the experiment described above. Table III shows that the stearate is very efficient, but palmitate and laurate display no availability. It is due to the inhibitory effect on bacterial growth that L-glutamic acid was not accumulated at all in the culture medium containing $1.0 \mathrm{mg}$ of the laurate per $\mathrm{ml}$ or $0.4 \mathrm{mg}$ of the palmitate per ml. Therefore, further investigation concerning culture conditions should be required. In the experimental result obtained above, it was found that at least there is some difference based on the length of carbon chain in the effect of the fatty acid esters.

\section{SUMMARY}

1. In the presence of sucrose fatty acid ester, Brevibacterium lactofermentum No. 2256 accumulated a large quantity of L-glutamic acid in the culture medium containing sufficient biotin $(20 \mu \mathrm{g} / \mathrm{l})$.

2. However, the sucrose fatty acid ester diminished the accumulation of L-glutamic acid in biotin deficient medium $(5 \mu \mathrm{g} / \mathrm{l})$.

3. These effects of the ester were lost, when it was added in the culture medium after over eight hours during incubation.

4. To the increments of biotin from 5 to $30 \mu \mathrm{g} / 1$, the corresponding amount of the ester was required for the accumulation of L-glutamic acid more than $40 \mathrm{mg} / \mathrm{ml}$. At higher levels than $2 \mathrm{mg} / \mathrm{ml}$, the ester was unable to display the effect owing to its insolubility.

5. Among the sucrose esters of several fatty acids sucrose monostearate was efficient. The observation concerning the effect of other fatty acid esters remains unsatisfactory.

Acknowledgment. The authors wish to thank the Central Research Laboratory, Dai-Nippon 
Sugar Manufacturing Co., Ltd. for supplying monostearate.

sucrose monolaurate, monopalmitate and 